\title{
A RELAÇÃO DA CADERINA-E COM O PROGNÓSTICO DO ADENOCARCINOMA COLORRETAL
}

\author{
THE RELATIONSHIP OF E-CADHERIN WITH COLORECTAL ADENOCARCINOMA \\ PROGNOSIS
}

\author{
Marcelo Betim Paes Leme, TCBC-RJ'; Ângela F L Waitzberg²; \\ Ricardo Artigiani ${ }^{3}$; Delcio Matos ${ }^{4}$
}

\begin{abstract}
RESUMO: Objetivo: Avaliar a relação da expressão da caderina-E com o intervalo livre de doença (ILD), com a sobrevida (S) e com o estadiamento de doentes operados por adenocarcinoma colorretal. Método: Foram estudados 89 doentes (41 homens e 48 mulheres) com média de idade de 62,3 anos. A distribuição segundo o estadiamento TNM foi: estádio I - 13 (14,6\%) doentes, estádio II - 29 $(32,6 \%)$, estádio III - $23(25,8 \%)$ e estádio IV - 24 (27,0\%). Sessenta e sete doentes foram submetidos à operação radical e acompanhados por um período médio de 37,9 meses. Os tumores foram examinados por técnica imuno-histoquímica e classificados como positivos ou negativos em relação à expressão da caderina-E. Resultados: A caderina-E foi positiva em 49,4\% e negativa em 50,6\% dos doentes. A recidiva ocorreu em $22,4 \%$ dos doentes e não esteve relacionada à expressão da caderina-E. Não foi observada relação da caderinaE com intervalo livre de doença e com a sobrevida. Também não foi verificada a associação da caderina-E $(p=0,958)$ com o estadiamento TNM. Conclusão: Os resultados verificados nesta pesquisa não permitem relacionar a expressão tissular da caderina-E com o estadiamento e o prognóstico do adenocarcinoma colorretal (Rev. Col. Bras. Cir. 2005; 32(4): 201-204).
\end{abstract}

Descritores: Caderinas; Neoplasias do cólon; Cirurgia colorretal; Cólon; adenocarcinoma; Reto.

\section{INTRODUÇÃO}

A importância das moléculas de adesão celular na etiologia das neoplasias está tornando-se cada vez mais evidente. Acredita-se também que a invasão tumoral e a disseminação metastática estejam relacionadas com algumas dessas moléculas ${ }^{1}$. No câncer colorretal, a transformação adenoma-carcinoma ocorre em consequiência às alterações genéticas que incluem algumas moléculas de adesão já identificadas, entre elas as proteínas caderina-E, cateninas, DCC e CD $44^{2,3}$.

A caderina-E tem sido relacionada como uma das principais proteínas envolvidas na adesão celular e está localizada particularmente no sítio epitelial ${ }^{3,4}$. Assim, quando pesquisada no tecido epitelial normal observa-se que sua expressão está sistematicamente preservada e distribuída de forma homogênea na membrana citoplasmática ${ }^{5}$. Por outro lado, tem-se observado que a ausência ou diminuição da proteína caderina-E em espécimes operatórios de câncer colorretal, tem estado associada a tumores com estádio mais avançado e à maior incidência de metástases linfonodais e hepáticas ${ }^{6,7}$.

Esta pesquisa baseou-se na hipótese de que tumores com menor adesão celular teriam maiores chances de desenvolver metástases.

\section{MÉTODO}

Neste estudo retrospectivo, foram avaliados 89 pacientes operados de câncer colorretal, na Disciplina de Gastroenterologia Cirúrgica do Hospital São Paulo - Universidade Federal de São Paulo. O Comitê de Ética aprovou o protocolo de pesquisa sem restrições.

As informações relativas ao estadiamento clínico e anatomopatológico, tratamento operatório e acompanhamento dos pacientes foram obtidas pela revisão dos prontuários (Quadro 1).

Foram excluídos do estudo doentes com tumores não ressecados ou tratados por ressecção local, doentes submetidos à radioterapia ou quimioterapia pré-operatória, doentes com tumores relacionados à polipose cólica familiar, retocolite ulcerativa e doença de Crohn e doentes com outras neoplasias.

A operação foi considerada radical em 67 (75,3\%) pacientes e paliativa em $22(24,7 \%)$. Convencionou-se como operação radical quando o cirurgião relatou ressecção completa da lesão e o estudo anatomopatológico do espécime operatório não demostrou comprometimento das margens de ressecção.

Os pacientes foram estadiados segundo a classificação $\mathrm{TNM}^{8}$ e estavam assim distribuídos: 13 pacientes no estádio I, 29 pacientes no estádio II, 23 pacientes no estádio III e 24 pacientes no estádio IV.

1. Professor de Clínica Cirúrgica do Centro Universitário de Volta Redonda - UNiFOA; Doutor em Medicina pela UNIFESP-EPM.

2. Professora Doutora do Departamento de Patologia da UNIFESP-EPM.

3. Médico Patologista do Hospital São Paulo; Mestre em Patologia pela UNIFESP-EPM.

4. Professor Livre Docente e Chefe do Grupo de Coloproctologia da Disciplina de Gastroenterologia Cirúrgica da UNIFESP-EPM.

Recebido em 15/02/2005

Aceito para publicação em 24/05/2005

Conflito de interesse: nenhum

Fonte de financiamento: nenhuma

Trabalho realizado na Disciplina de Gastroenterologia Cirúrgica do Hospital São Paulo da Universidade Federal de São Paulo-Escola Paulista de Medicina. 


$\begin{array}{lc}\text { Pacientes } & \\ \quad \text { Número } & 89 \\ \text { Idade (média) } & 62,3 \text { anos } \\ & n(\%) \\ \text { Sexo } & \\ \quad \text { Masculino } & 41(46,1) \\ \quad \text { Feminino } & 48(53,9) \\ \text { Localização do Tumor } & \\ \text { Cólon direito } & 25(28,1) \\ \text { Cólon esquerdo } & 19(21,3) \\ \text { Reto } & 45(50,6) \\ \text { Critério de radicalidade da operação } & \\ \text { Radical } & 67(75,3) \\ \text { Paliativa } & 22(24,7) \\ \text { Estádio (TNM) } & \\ \text { I } & 13(14,6) \\ \text { II } & 29(32,6) \\ \text { III } & 23(25,8) \\ \text { IV } & 24(27,0)\end{array}$

Quadro 1 - Distribuição dos doentes quanto à média das idades, sexo, localização do tumor, critério de radicalidade da operação e estádio TNM.

A expressão da caderina-E foi avaliada em relação ao estadiamento TNM, a recidiva, o intervalo livre de doença (ILD) e a sobrevida (S). Considerou-se como recidiva o ressurgimento de doença neoplásica, loco-regional ou em órgãos à distância, cuja detecção tenha sido realizada por exame físico, endoscópico ou de imagem, sem necessidade de comprovação histológica; como ILD o tempo decorrido entre a data da operação e a última revisão na qual não foi detectada recidiva neoplásica e como sobrevida o intervalo de tempo decorrido entre a data da operação e o desfecho de óbito.

Dos blocos de parafina, utilizados no estudo histopatológico foram produzidas novas lâminas histológicas, com cortes de $4 \mathrm{~mm}$, todos correspondentes ao ponto de maior penetração do tumor na parede intestinal, com finalidade de padronização da amostra. A proteína caderina-E foi evidenciada por exame imuno-histoquímico, pela técnica da estreptoavidina-biotina-peroxidase, utilizando-se o anticorpo monoclonal anti-caderina-E, diluição 1/100 (NCH-38®, DAKO).

A avaliação da caderina-E, por método semiquantitativo, foi realizada por leitura das lâminas histológicas em microscópio óptico com aumento de 400x. Os achados foram considerados positivos quando se detectou a presença da proteína na membrana celular em $50 \%$ das células tumorais e negativos quando se verificou menos de $50 \%$ de células tumorais positivas para caderina-E ou quando a localização da proteína estivesse fora da membrana celular ${ }^{9}$.

As avaliações foram realizadas sem conhecimento do estádio clínico-patológico e do estudo histológico pela coloração hematoxilina-eosina. Foram utilizados dois avaliadores que classificaram os casos em conjunto e em comum acordo.

Os resultados foram submetidos à análise estatística e considerou-se como significativo valores de $\mathrm{p}<0,05$ ou $5 \%$. A avaliação da associação entre o estadiamento e a expressão da caderina-E foi realizada pelo teste Qui-quadrado de Pearson. Utilizou-se o estimador de Kaplan-Meier no estudo da associação entre expressão tissular da caderina-E e o intervalo livre de doença e sobrevida. O teste de Wilcoxon (versão Breslow) foi aplicado na comparação entre as curvas obtidas.

\section{RESULTADOS}

A caderina-E, avaliada em 89 doentes, apresentou expressão positiva em $44(49,4 \%)$ doentes e negativa em 45 $(50,6 \%)$. Não foi verificada a relação do estadiamento TNM com a expressão da caderina-E (Tabela 1).

Os doentes submetidos à operação radical $(n=67)$ foram acompanhados por um período médio de 37,9 meses, o que permitiu detectar a recorrência da doença neoplásica em $15(22,4 \%)$ pacientes, sendo oito recidivas à distância. Neste mesmo período foram observados 20 óbitos, dos quais 11 foram relacionados a causas gerais e nove à doença neoplásica.

Observou-se freqüência semelhante de recidivas em doentes com expressão positiva (sete recidivas) e negativa da proteína caderina-E (oito recidivas).

Também foram comparados o intervalo livre de doença (ILD) e a sobrevida (S) de doentes com expressão positiva e negativa da proteína caderina-E e não se observou diferença entre os dois grupos.

\section{DISCUSSÃO}

A adesão celular não deve ser entendida como um fenômeno estático com efeito limitado à função de "cimento" intercelular. Freqüentemente as moléculas envolvidas nesse processo, além da função de ligação, permitem a transmissão de sinais reguladores e a troca de informações entre células. Assim, a interação, mediada por essas moléculas, permite às células organizarem-se em grupos e formarem estruturas complexas, bem como participar da organogênese e da reconstrução tissular ${ }^{10,11}$.

Distúrbios na interação celular normal podem ocorrer pela baixa produção de moléculas de adesão ou por bloqueio em sua ação, permitindo novas interações celulares e a disseminação dessas células fora do seu sítio original. Esses eventos poderiam explicar uma ou mais etapas no processo de carcinogênese.

As caderinas formam uma família de glicoproteínas transmembrana, cuja função de adesão célula-célula é cálcio

Tabela 1 - Distribuição da expressão da caderina-E segundo estadiamento TNM.

\begin{tabular}{lrccc}
\hline & & \multicolumn{2}{c}{ Caderina-E } & \\
\cline { 2 - 4 } & & Negativo & Positivo & Total \\
\hline TNM & I & 7 & 6 & 13 \\
& II & 14 & 15 & 29 \\
& III & 11 & 12 & 23 \\
& IV & 13 & 11 & 24 \\
Total & & 45 & 44 & 89 \\
\hline
\end{tabular}

$p=0,958$ (Qui-quadrado de Pearson) 
dependente. Sua porção intracelular se liga a um grupo de proteínas chamadas cateninas, que por sua vez se ligam ao citoesqueleto. A caderina-E tem sido relacionada como uma das principais proteínas envolvidas na adesão celular ${ }^{3,4}$ e se supõem que alterações em sua expressão poderiam relacionar-se com prognóstico do adenocarcinoma colorretal ${ }^{5,12}$.

$\mathrm{Na}$ literatura não existe consenso quando considerar a reação imuno-histoquímica da proteína caderina-E positiva. Assim aceita-se como reação normal ou positiva aquela que ocorre na membrana celular. Entretanto quando se avalia em que percentual mínimo as células tumorais devem expressar a caderina-E para que o tumor seja considerado como produtor normal da proteína, as medidas são muito variáveis, situandose entre 25 e $90 \%{ }^{5,9,13,14}$. Questiona-se também se não poderiam existir tumores que avaliados pelo método imuno-histoquímico, expressassem a caderina-E com características histológicas normais mas destituída de função biológica, por exemplo, pela falta de expressão das cateninas citoplasmáticas ${ }^{14}$.

Essa possibilidade foi avaliada por Ghadimi et al ${ }^{15}$ que verificaram presença de caderina-E normal e catenina alterada em $15 \%$ dos casos. Acredita-se entretanto, que nesta situação haveria uma distribuição anormal da caderina-E que estaria então localizada no citoplasma ou interstício ${ }^{16}$. Isto talvez explique a localização citoplasmática da caderina-E em vários casos dessa pesquisa. Quando isto ocorria, o tumor era classificado como negativo.

De um modo geral tem-se criticado a avaliação de marcadores tumorais em cortes histológicos, devido a heterogeneidade das células tumorais que, por não estarem distribuídas uniformemente dificultariam a detecção e quantificação de todas as alterações histopatológicas e moleculares ocorridas na neoplasia ${ }^{17}$.

A expressão da caderina-E estudada por técnica imuno-histoquímica é freqüentemente medida por método semiquantitativo, o que implica em elevado grau de subjetividade da medida. Deve-se ressaltar, entretanto, que algumas pesquisas verificaram concordância entre resultados encon- trados por método imuno-histoquímico e estudos genéticos e de biologia molecular ${ }^{18,19}$.

Ainda não está clara a relação entre a evolução do estadiamento clínico-patológico e alterações na expressão da caderina-E. Alguns autores observaram menor freqüência na expressão da caderina-E em tumores colorretais com estadiamento mais avançado ${ }^{5,19,20}$. Esses resultados entretanto não são uniformes. Nesta pesquisa não se observou relação entre a expressão da caderina-E e estadiamento clínico-patológico. Resultados semelhantes foram verificados por outros autores ${ }^{15,21}$.

A expressão tissular caderina-E também pode estar relacionada à sobrevida de doentes operados de câncer colorretal. Em geral as pesquisas têm revelado uma relação positiva entre a expressão de proteínas de adesão celular e sobrevida ${ }^{12}$. Ikeguchi et $a l^{9}$ e Dorudi et al ${ }^{22}$ verificaram relação entre os níveis de caderina-E e a sobrevida de doentes com câncer colorretal, observando que a maior expressão de caderina-E correspondia a melhor curva de sobrevida. Kimura et al ${ }^{7}$ observaram curvas de sobrevida desfavoráveis para doentes com expressão reduzida da caderina-E. Os resultados foram submetidos à análise multivariada que confirmou a baixa expressão da caderina-E como um fator de mau prognóstico. Outros autores, entretanto, verificaram que a baixa expressão da caderina-E ocorria na mesma medida em que havia progressão do estadiamento clínicopatológico ${ }^{5,20}$, o que de certa forma limitaria sua utilização como fator prognóstico para uso clínico.

Neste estudo a análise de sobrevida, pelo método de Kaplan-Meier, não detectou diferença entre doentes com expressão tissular positiva e negativa da proteína caderina-E. Resultados semelhantes foram observados por Hugh et $a l^{23} \mathrm{e}$ Schuhmacher et al ${ }^{24}$.

Portanto, nós acreditamos que o papel da expressão tissular da caderina-E na avaliação prognóstica do câncer colorretal ainda permanece indefinido. Assim sua utilização na prática clínica, no momento, não deve ser estimulada devendo-se restringir seu uso à área da pesquisa.

\begin{abstract}
Background: To evaluate the relationship between E-cadherin and recurrence, relapse free survival, overall survival and TNM system in patients operated on for colorectal adenocarcinoma. Methods: This study included 89 patients (41 men and 48 women, mean age 62.3 years) who underwent colorectal ressection for adenocarcinoma. Of these patients, 13 (14.6\%) had TNM stage I disease, 29 (32.6\%) stage II, 23 (25.8\%) stage III and 24 (27.0\%) stage IV. Sixty-seven patients had been treated by curative resection and their mean follow-up was 37.9 months. Paraffin-embedded tumor specimens were immunohistochemically stained to cadherin-E and assessed as positive and negative. Results: E-cadherin was positive in $49.4 \%$ of the patients and negative for the remaining $50.6 \%$. The disease recurred in $22.4 \%$ of the patients and there was no relation with E-cadherin expression. Likewise, there was no relationship between E-cadherin and relapse free survival or overall survival. No significant association has been show between E-cadherin $(p=0.958)$ and TNM system. Conclusion: These results do not allow us to associate Ecadherin with the TNM system and prognosis of patients with colorectal adenocarcinoma.
\end{abstract}

Key words: Cadherins; Colonic Neoplasms; Colorretal surgery; Colon; Adenocarcinoma; Rectum.

\section{REFERÊNCIAS}

1. Jiang WG. E-cadherin and its associated protein catenins, cancer invasion and metastasis. Br J Surg. 1996; 83(4):437-46.
2. Perl AK, Wilgenbus P, Dahl U, et al. A causal role for E-cadherin in the transition from adenoma to carcinoma. Nature. 1998; 392(6672):190-3.

3. Mikami T, Mitomi H, Hara A, et al. Decreased expression of CD44, alpha-catenin, and deleted colon carcinoma and altered 
expression of beta-catenin in ulcerative colitis-associated dysplasia and carcinoma, as compared with sporadic colon neoplasms. Cancer. 2000; 89(4):733-40.

4. Shiozaki H, Oka H, Inoue M, et al. E-cadherin mediated adhesion system in cancer cells. Cancer. 1996; 77(8 Suppl):1605-13.

5. Mohri Y. Prognostic significance of E-cadherin expression in human colorectal cancer tissue. Surg Today. 1997; 27(7):606-12.

6. Kitagawa T, Matsumoto K, Nagafuchi A, et al. Co-expression of E-cadherin and a-catenin molecules in colorectal cancer. Surg Today. 1999; 29(6):511-8.

7. Kimura T, Tanaka S, Haruma K, et al. Clinical significance of MUC1 and E-cadherin expression, cellular proliferation, and angiogenesis at the deepest invasive portion of colorectal cancer. Int J Oncol. 2000; 16(1):55-64.

8. UICC - Union Internationale Contre le Cancer. TNM Classification des tumeurs malignes. 5 $^{\mathrm{e}}$ ed. Paris: Cassini; 1998.

9. Ikeguchi M, Taniguchi M, Makino M, Kaibara N. Reduced Ecadherin expression and enlargement of cancer nuclei strongly correlate with hematogenic metastasis in colorectal adenocarcinoma. Scand J Gastroenterol. 2000; 35(8):839-46.

10. Takeichi M. Cadherins: a molecular family important in selective cell-cell adhesion. Annu Rev Biochem. 1990; 59:237-52.

11. Johnson JP. Cell adhesion molecules of the immunoglobulin supergene family and their role in malignant transformation and progression to metastatic disease. Cancer Metastasis Rev. 1991; 10(1):11-22.

12. Ikeguchi M, Makino M, Kaibara N. Clinical significance of Ecaderin-catenin complex expression in metastatic foci of colorectal carcinoma. J Surg Oncol. 2001; 77(3):201-7.

13. Ilyas M, Novelli M, Wilkinson $\mathrm{K}$, et al. Tumor recurrence is associated with Jass grouping but not with differences in Ecadherin expression in moderately differentiated Dukes' B colorectal cancers. J Clin Pathol. 1997; 50(3):218-22.

14. Gofuku J, Shiozaki H, Tsujinaka T, et al. Expression of Ecadherin and alpha-catenin in patients with colorectal carcinoma. Correlation with cancer invasion and metastasis. Am J Clin Pathol. 1999; 111(1):29-37.

15. Ghadimi BM, Behrens, Hoffmann I, et al. Immunohistological analysis of E-cadherin, alpha-, beta- and gamma-catenin expression in colorectal cancer: implications for cell adhesion and signaling. Eur J Cancer. 1999; 35(1):60-5.
16. Takeichi M. Cadherin cell adhesion receptors as a morphogenetic regulator. Science. 1991; 251(5000):1451-5.

17. Baisse B, Bouzourene H, Saraga EP, et al. Intratumor genetic heterogeneity in advanced human colorectal adenocarcinoma. Int J Cancer. 2001; 93(3):346-52.

18. Kanazawa T, Watanabe T, Kazama S, et al. Poorly differentiated adenocarcinoma and mucinous carcinoma of the colon and rectum show higher rates of loss of heterozygosity and loss of Ecadherin expression due to methylation of promoter region. Int J Cancer. 2002; 102(3):225-9.

19. Garinis GA, Menounos PG, Spanakis NE, et al. Hypermethylation-associated transcriptional silencing of Ecadherin in primary sporadic colorectal carcinomas. J Pathol. 2002; 198(4):442-9.

20. Dorudi S, Sheffield P, Poulsom R, et al. E-cadherin expression in colorectal cancer. An immunocytochemical and in situ hybridization study. Am J Pathol. 1993; 142(4):981-6.

21. Nigam AK, Savage FJ, Boulos PB, et al. Loss of cell-cell and cell-matrix adhesion molecules in colorectal cancer. Br J Cancer. 1993; 68(3):507-14.

22. Dorudi S, Hanby AM, Poulsom R, et al. Level of expression of E-cadherin mRNA in colorectal cancer correlates with clinical outcome. Br J Cancer. 1995; 71(3):614-6.

23. Hugh TJ, Dillon AS, Taylor BA, et al. Cadherin-catenin expression in primary colorectal cancer: a survival analysis. $\mathrm{Br}$ J Surg. 1999; 80(7):1046-51.

24. Schuhmacher C, Becker I, Oswald S, et al. Loss of immunohistochemical E-cadherin expression in colon cancer is not due to structural gene alterations. Virchows Arch. 1999; 434(6):489-95.

Endereço para correspondência :

Marcelo Betim Paes Leme

Rua Moacir de Paula Lobo, 19

Limoeiro

27283-350 - Volta Redonda - RJ

Tel: (24) 33462288

Fax: (24) 33422766

E-mail:marcelo.leme@uol.com.br 